\title{
MODELING OF MONOCRYSTALLINE MAGNESIUM MICROBEAM BENDING
}

\author{
JIŘí NĚMEČEK ${ }^{a, *}$, JAN MAŇÁKK ${ }^{b}$, JIŘí NĚMEČEK ${ }^{a}$ \\ ${ }^{a}$ Czech Technical University in Prague, Faculty of Civil Engineering, Department of Mechanics, Thákurova 7 , \\ 16629 Prague 6, Czech Republic \\ ${ }^{b}$ Institute of Physics of ASCR, Na Slovance 1999/2, 182 21 Prague 8, Czech Republic \\ * corresponding author: jiri.nemecek.1@fsv.cvut.cz (Ph.D. candidate)
}

\begin{abstract}
This paper presents a numerical simulation of a micro-scale experiment on a magnesium alloy. Micro cantilever beams were fabricated using Focused Ion Beam technology in a single crystal of $\mathrm{Mg}$. The cantilever beams have dimensions in the order of a few micrometers and a pentagonal cross section. Nanoindenter was used for cantilever beam bending and load-displacement curve was received. Cantilevers with two different crystallographic orientations were chosen for the experiment. Three dimensional numerical FE model with elastoplastic behavior respecting crystal anisotropy was used to fit experimental load displacement curves. Strengths and deformation energy were evaluated from the models for each cantilever.
\end{abstract}

KEyworDs: Magnesium, microbeams, crystal anisotropy, FE model.

\section{INTRODUCTION}

Magnesium crystallizes in a hexagonal close packed structure (HPC) with various deformation mechanisms such as basal plane slipping $\{0001\}<1120>$, prismatic slip $\{1010\}<1120>$ and pyramidal slip $\{1011\}<1123>$ or twinning $\{1012\}<1011>$ [1]. The deformations start from a defect or on boundaries between different crystalline grains. In the first scenario, slipping happens when the crystal planes slide along each other and in the second, twinning is a concentrated shift of atomic positions [2].

Magnesium alloys fulfill the demand for a lightweight construction material with good recycling potential. Nowadays magnesium is commonly used in automotive, train and aircraft industry for its high tensile strength, low strength to weight ratio and excellent corrosion resistance. However, magnesium also has negative properties such as tendency for cracking and brittle failure which is probably given due to intercrystalline failure and local transcrystalline fracture at twin zone [3, 4].

Nanoindentation is a powerful tool which uses a small diamond tip pressed into the material to measure mechanical properties such as modulus of elasticity, hardness and creep from load-displacement curves [5]. Nanoindentation usually operates at microscale and is a perfect tool for measuring properties of an individual crystal. Besides classical nanoindentaion testing there are possibilities to use nanoindenter tip for bending microscale samples. Micrometer samples can be fabricated using Focused Ion Beam (FIB) technology. FIB instrument is very similar to a scanning electron microscope (SEM) but instead of electrons it uses Gallium ions to hit the material and cause its milling 6 . FIB energy is typically between 10 and $50 \mathrm{kV}$, with beam currents varying between $1 \mathrm{pA}$ and $10 \mathrm{nA}$ [7] and is capable of creating samples with varied geometry, mostly pillars or triangular and pentagonal micro beams. Micro-beam bending is advantageous for evaluating tensile strength and fracture energy.

In this work, micro cantilevers beams were tested in specific crystal directions where twinning occurs. During the testing, load-displacement curves were measured. Also, a simple numerical model with good reproducibility of the curves gained on different crystalline orientations has been developed.

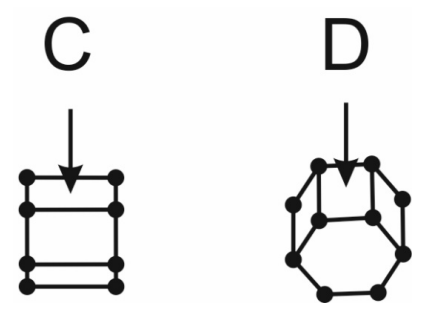

FiguRE 1. Crystal orientation with respect to loading direction.

\section{EXPERIMENTAL PART}

A sample from pure magnesium was prepared. The sample was cut by a precise diamond saw and finely polished to achieve average roughness in the range of a few nanometers. EBSD (Electron backscatter diffraction) was performed on the polished surface to find its crystal orientation. Micro beams were fabricated on the identified places by the FEI Quanta 3D FEG dual beam instrument combining SEM and FIB. All samples were micro cantilever beams with length of about $22 \mu \mathrm{m}$ and have a pentagonal cross section with a width of about $3 \mu \mathrm{m}$ and variable height 

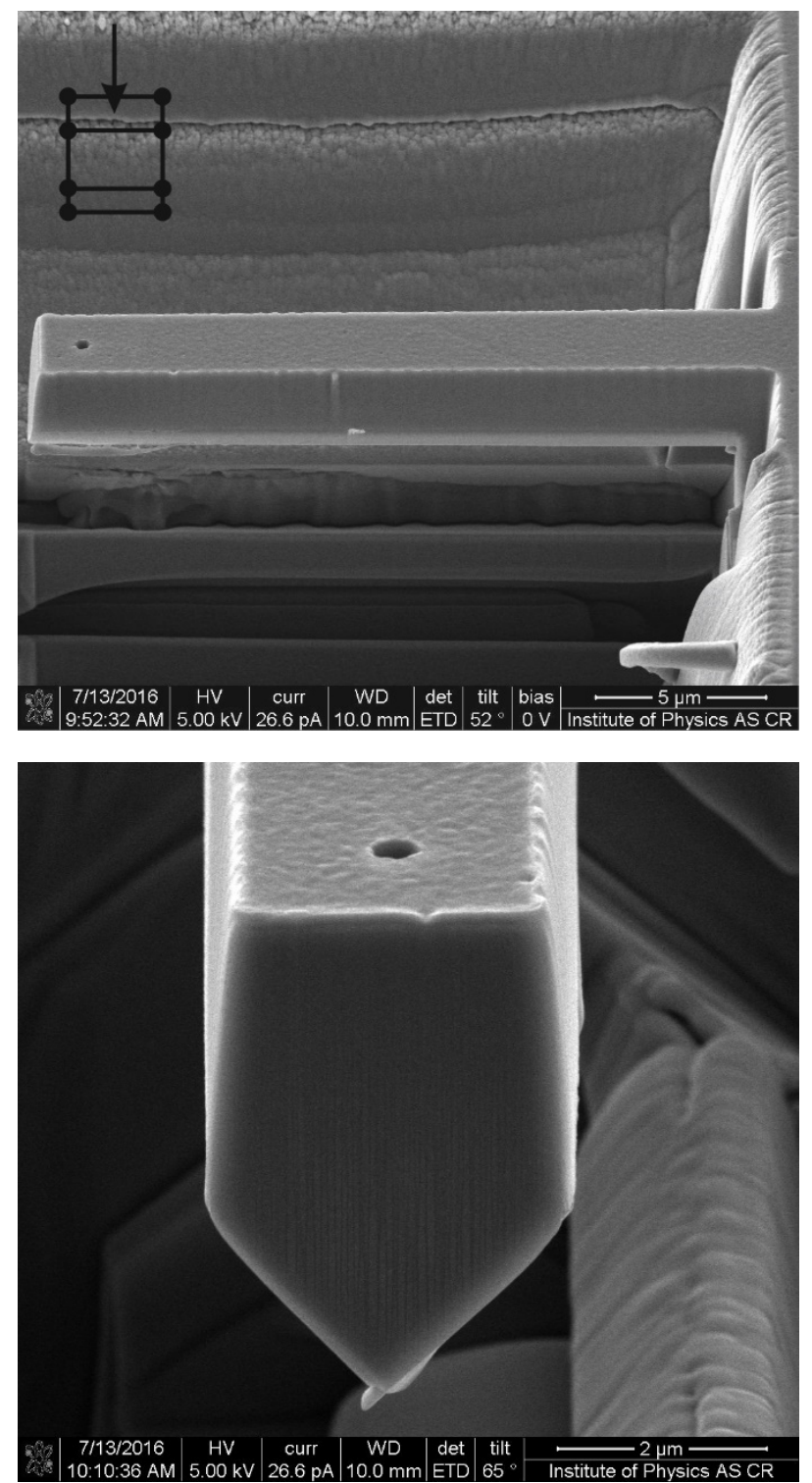

Figure 2. SEM images of fabricated micro beam with C crystal orientation: side view (top) and front view (bottom).

from 3.5 to $5 \mu \mathrm{m}$. Two types of cantilevers with two prismatic orientations, labelled $\mathrm{C}$ and $\mathrm{D}$, were created, see Figure 1. SEM images of the fabricated cantilevers are shown in Figures 2 and 3 .

Circle marks were created on each cantilever approximately $2 \mu \mathrm{m}$ away from the free end. At this mark, nanoindentation was performed with a Berkovich tip to bend the cantilever. Standard displacement controlled tests were performed with a constant increment of displacement up to a maximal value of $3000 \mathrm{~nm}$. In total, four cantilevers were bent for each orientation, however, the curves had the same trend. In this paper were picked only the typical curves. Typical experimental load-displacement curves measured are shown in Figure 5. In both cases firstly, elastic deformation characterized by reversible response of the lattice to the displacement. Secondly, plastic deformation of the crystal, caused mostly by twinning for the cases
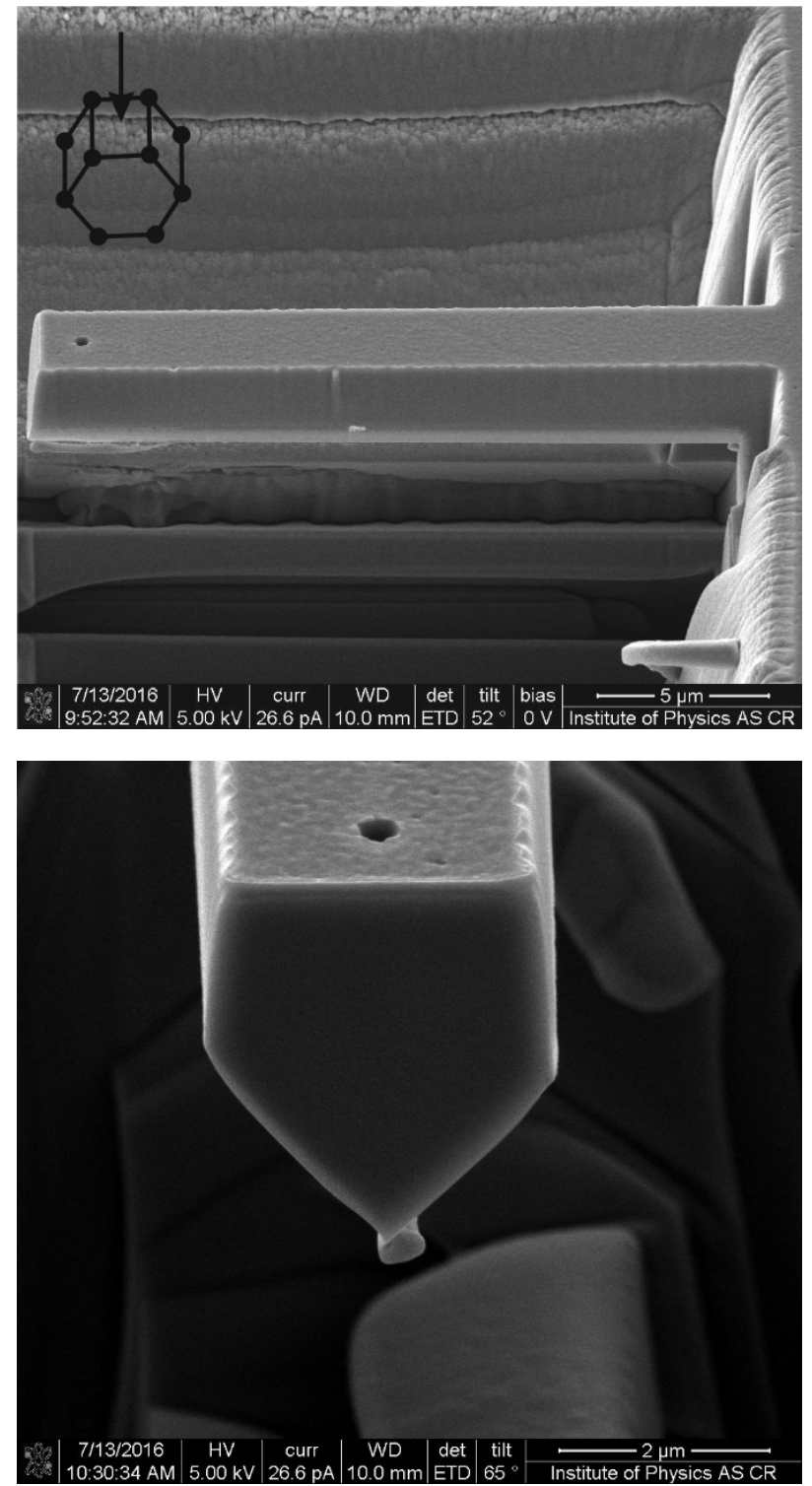

Figure 3. SEM images of fabricated micro beam with D crystal orientation: side view (top) and front view (bottom).

of magnesium crystal orientations, takes place. After reaching a critical strain, twinning causes a release of energy that is demonstrated as a radical drop of load in Figure 5

\section{Numerical MODELLING}

A numerical model was created in ANSYS Workbench software 17.2. A three dimensional model was proposed due to the irregular cross section of the cantilever micro beam and due to previous experience of authors with micro beam modelling [10]. Material constants for elastic anisotropy of pure $\mathrm{Mg}$ were taken from the literature [8, 9] and are given in Table 1 . For the hexagonal crystal, five independent elastic constants are needed and a sixth is calculated from 


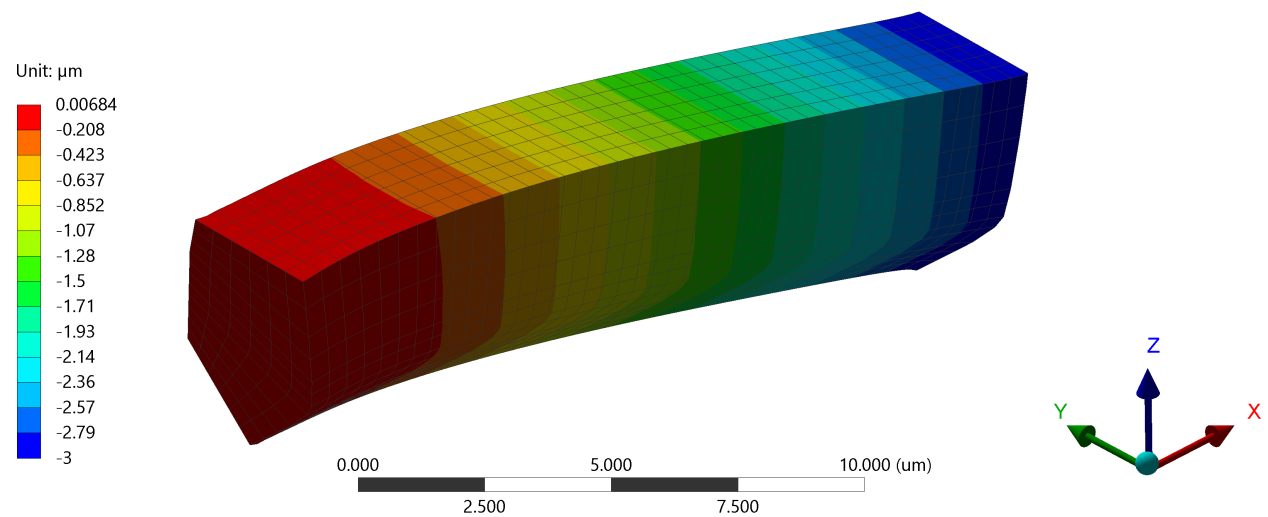

Figure 4. Directional deformation ( $\mathrm{Z}$ axis) at maximal prescribed displacement $3 \mu \mathrm{m}$ of the cantilever labelled as $\mathrm{C}$ with shown mesh.

\begin{tabular}{lcccccc}
\hline & $\mathrm{C}_{11}[\mathrm{GPa}]$ & $\mathrm{C}_{12}[\mathrm{GPa}]$ & $\mathrm{C}_{13}[\mathrm{GPa}]$ & $\mathrm{C}_{33}[\mathrm{GPa}]$ & $\mathrm{C}_{44}[\mathrm{GPa}]$ & $\mathrm{C}_{66}[\mathrm{GPa}]$ \\
\hline Basal & 58.58 & 25.02 & 20.79 & 61.11 & 16.58 & 16.78 \\
Prismatic & 61.11 & 20.79 & 25.02 & 58.58 & 16.58 & 20.16 \\
\hline
\end{tabular}

TABLE 1. Elastic constant of pure Mg for basal and prismatic crystal orientation [8, 9].

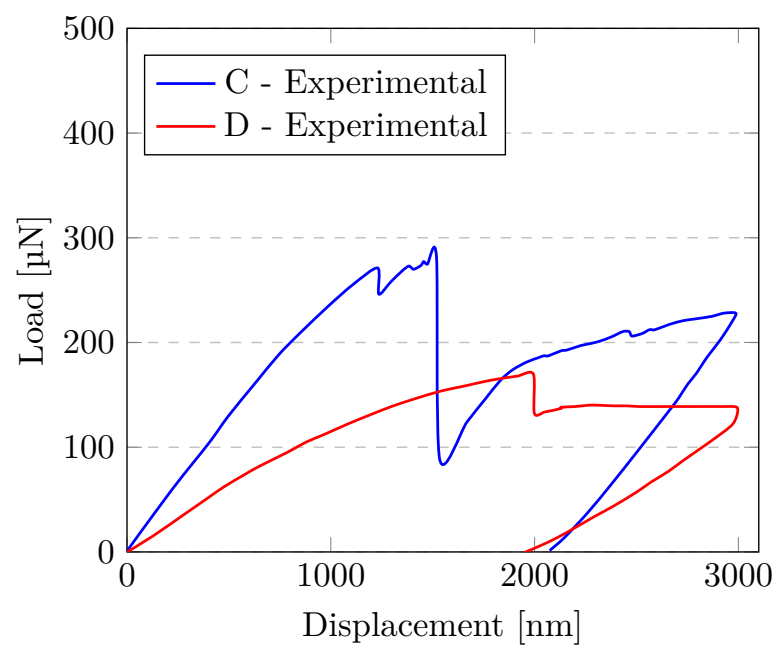

FiguRE 5. Typical experimental load-displacement curves of two different crystal orientations measured during cantilever bending.

\begin{tabular}{|c|c|c|}
\hline \multirow{2}{*}{ Plastic strain $\left[\mu \mathrm{m} \mu \mathrm{m}^{-1}\right]$} & \multicolumn{2}{|c|}{ Stress $[\mathrm{MPa}$} \\
\hline & $\mathrm{C}$ & $\mathrm{D}$ \\
\hline 0 & 392 & 260 \\
\hline 0.07 & 470 & 410 \\
\hline 0.010 & 495 & 420 \\
\hline 0.015 & 530 & 425 \\
\hline 0.020 & 545 & 430 \\
\hline
\end{tabular}

TABle 2. Plasticity data for the two Prismatic orientations of crystal C and D. the equation

$$
C_{66}=\frac{1}{2}\left(C_{11}-C_{12}\right)
$$

The constants are given for basal crystal orientation only and need to be transformed for prismatic orientation.

Plasticity of the beams was modelled with multilinear isotropic hardening. The Yield stress was directly calculated from the bending experiment, where the values for cantilevers $\mathrm{C}$ and $\mathrm{D}$ are $392 \mathrm{MPa}$ and $260 \mathrm{MPa}$ respectively. The data of plastic strain and stress are shown in Table 2. The cantilever is filled with 3-D SOLID186 elements which are defined by 20 nodes and have three degrees of freedom per node, translation in the nodal $\mathrm{x}, \mathrm{y}$, and $\mathrm{z}$ directions. This element supports von Mises plasticity and is suitable for large deflection [11. The boundary conditions were set similar to the real cantilever with fixed support on one end and a displacement increment of up to $3000 \mathrm{~nm}$. The deformed shape of the cantilever model is shown in Figure 4

The deformation process of cantilever bending can be characterized with deformation energy. A part of the total deformation energy that occurs before the first twinning was calculated from the stress-strain curves as follows

$$
G=\int_{0}^{\epsilon_{\text {crit }}} \sigma d \epsilon
$$

where $\sigma$ is the axial stress and $\epsilon_{\text {crit }}$ is the critical strain when the first twinning happens. 


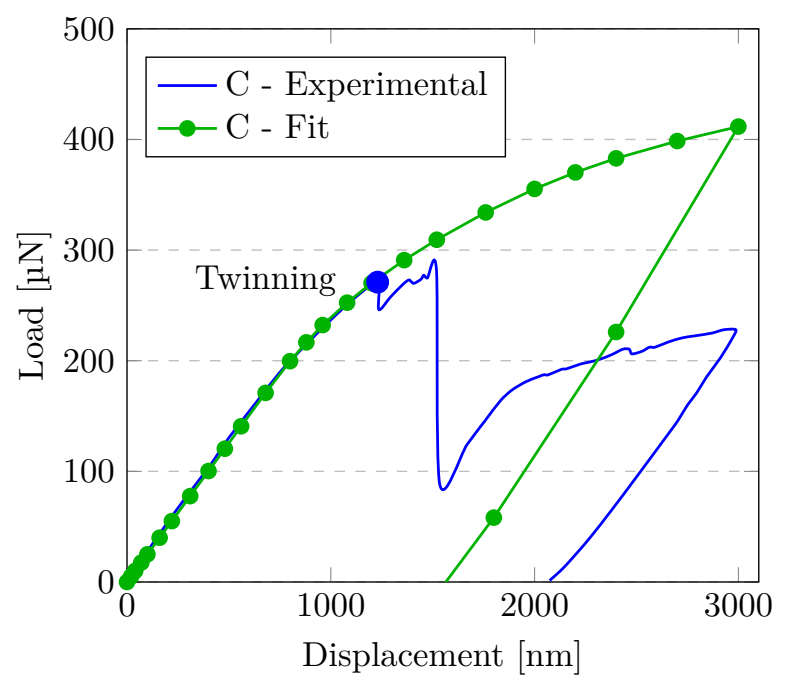

Figure 6. Experimental and calculated loaddisplacement curves of $\mathrm{C}$ prismatic crystal orientation with marked the first twinning.

\section{Results AND Discussion}

Calculated load-displacement curves can be seen in Figures 6 and 7. In both cases fitting curves exhibit the same behavior as in the experiment on the elastic part that matches perfectly. The curves are also with good agreement after Yield point until the first twining which is observed on the experimental curves when a radical drop of load occurs. Unfortunately this drop brings very difficult task for modelling and it was not considered in this work. According to research on austenitic high managanese steels showing twinning-included plasticity by C.Y. Sun et al. [12], it would be necessary to employ crystal plasticity incorporating the twinning mechanism, where eighteen material constants are needed to be obtained experimentally. The first twinning, labelled as $w_{\text {crit }}$, occurs at displacement of $1.2 \mu \mathrm{m}$ for $\mathrm{C}$ and $2 \mu \mathrm{m}$ for $\mathrm{D}$ orientation. The shape of the fitting curves after twinning has the same trend and would match well with the experimental curve if no twinning had happened with only one exception. The slope of the un-loading curve for $\mathrm{D}$ orientation is slightly different.

The axial stress in the $\mathrm{X}$ axis direction is shown in Figure 9. The strain was calculated as the equivalent total strain composed from elastic strain and equivalent plastic stain computed of von Mises criterion. Stress-strain curves calculated at the top fixed end of the cantilever are shown in Figure 8. However, this diagram is again partly correct till the $w_{\text {crit }}$ value; the data after this point are not relevant. Thus, critical strain $\left(\epsilon_{\text {crit }}\right)$ and stress were deducted from the model. The normal stress till the first drop of load is $619.9 \mathrm{MPa}$ with a strain of 0.0323 for the $\mathrm{C}$ cantilever and $592.9 \mathrm{MPa}$ with value of strain 0.0548 . The stress-strain curves made it possible to compare the deformation behavior of micro-beams with different orientations. Based on this comparison, the

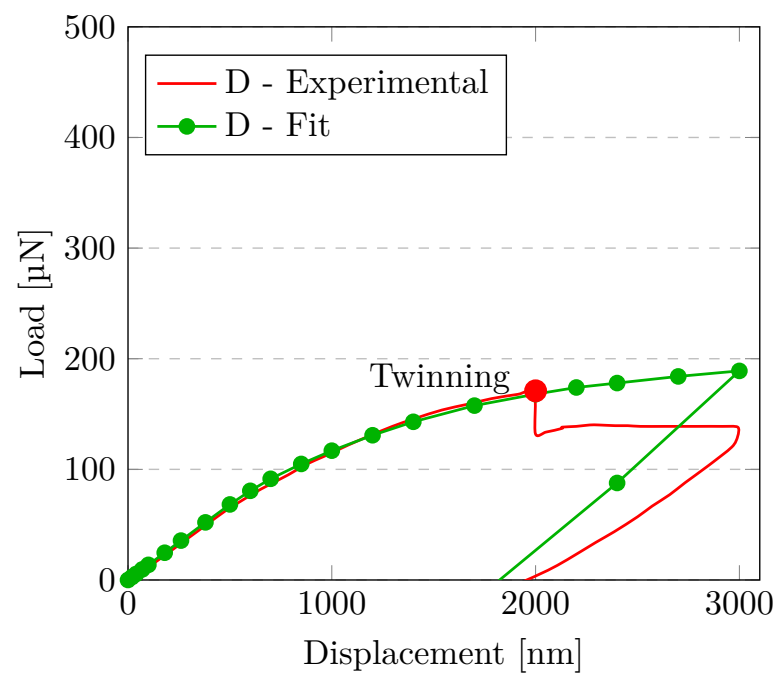

Figure 7. Experimental and calculated loaddisplacement curves of D prismatic crystal orientation with marked the first twinning.

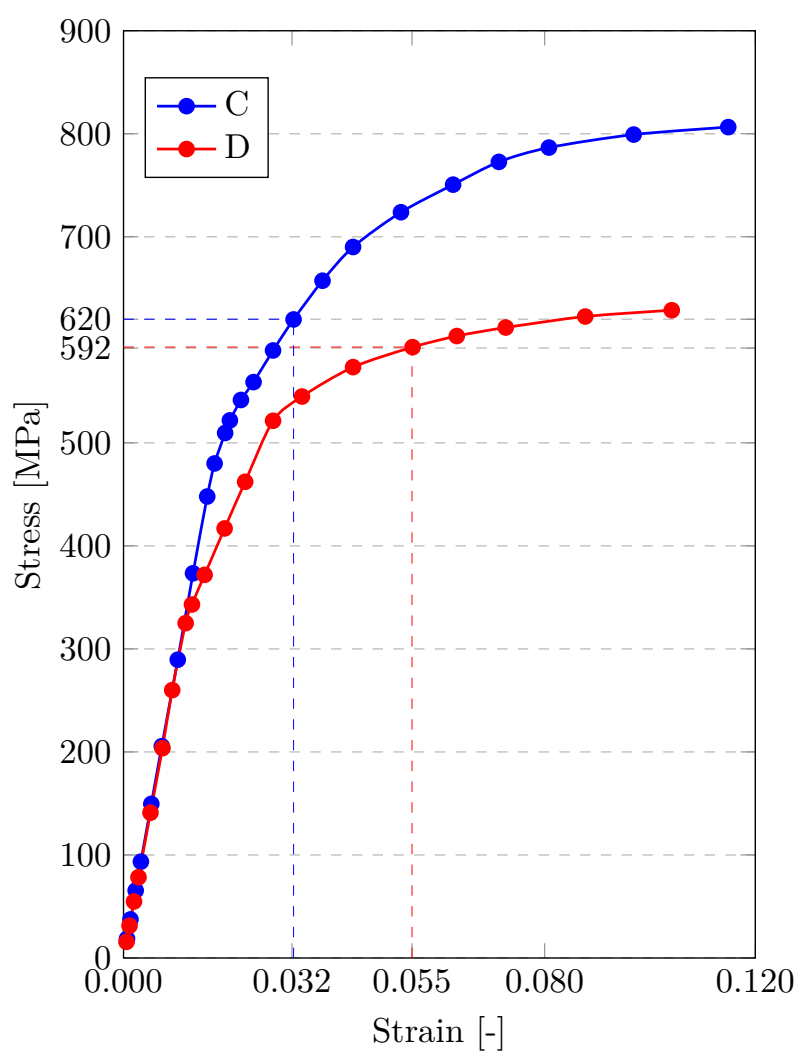

Figure 8. Calculated stress-strain curves of $\mathrm{C}$ and D prismatic crystal orientations with labelled critical stresses and strains.

Yield point is higher for $\mathrm{C}$ orientation while the stored energy before the first twinning is higher for $\mathrm{D}$.

The energies calculated according to Equation 2 for $\mathrm{C}$ and $\mathrm{D}$ are $16.09 \mathrm{Jm}^{-3}$ and $28.08 \mathrm{Jm}^{-3}$, respectively. That makes $\mathrm{D}$ orientation more ductile. 


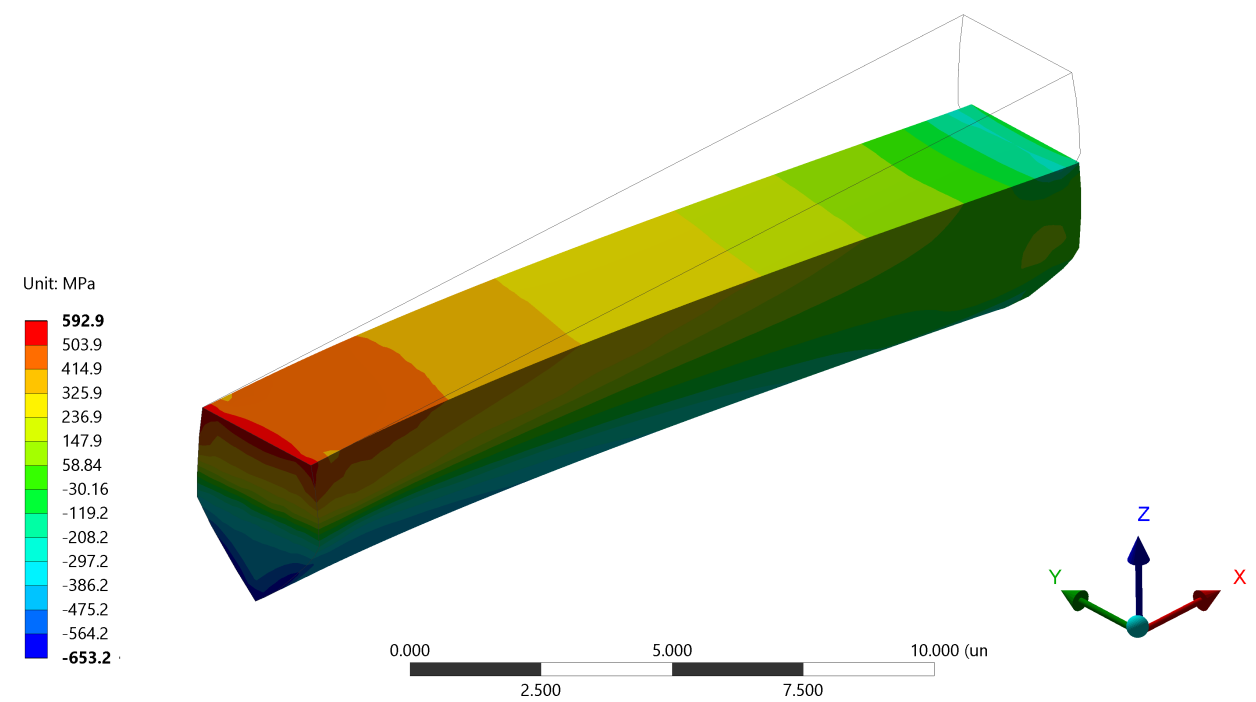

Figure 9. Deformed shape and axial stress (X axis) at critical displacement of $2 \mu \mathrm{m}$ with uninformed wireframe of D cantilever beam.

\section{Conclusions}

This paper shows numerical modelling of micro cantilever beams made from pure magnesium with two prismatic orientations of the crystals. The elastic part, modelled with five independent anisotropic constants, gave a perfect match to the experiments. Inelastic deformations were captured with isotropic plasticity with multilinear hardening law until the first twinning. The twinning mechanism was not captured and left for future work. It was found that the fitting curves have the same trend as experimental curves if the twinning was removed, which suggests that the model is correct and only the twinning mechanism needs to be incorporated using e.g.crystal plasticity by Sun et al. [12].

Critical displacements $w_{\text {crit }}$, corresponding to the critical strains and stresses at the time of the first twinning were evaluated. It was found that the critical stress for $\mathrm{C}$ orientation is $30 \mathrm{MPa}$ higher compared to D. However, the critical strain is higher for D. Thus, the deformation energy stored in the material before the first twinning is higher for D.

\section{LIST OF SYMBOLS \\ $w_{\text {crit }}$ Displacement at first twinning $[\mathrm{nm}]$ \\ $\epsilon_{\text {crit }}$ Strain at first twinning [-] \\ $\sigma \quad$ Axial stress (X axis) [MPa] \\ $G$ Deformation energy $\left[\mathrm{J} \mathrm{m}^{-3}\right]$ \\ $C_{66}$ Elastic constant \\ FIB Focused ion beam \\ $S E M$ Scanning electron microscope \\ $E B S D$ Electron backscatter diffraction}

\section{ACKNOWLEDGEMENTS}

Financial support of the Czech Science Foundation (projects 17-18652S) is gratefully acknowledged.

\section{REFERENCES}

[1] K. Fukuda, Y. Koyanagi, M. Tsushida, et al. Activation stress for slip systems of pure magnesium single crystals in pure shear test. Materials transactions 58(4):587-591, 2017.

[2] N. K. Bourne. Unexpected twins. Physics 9:19, 2016.

[3] F. Kaiser, K. Kainer. Magnesium alloys and technology. John Wiley \& Sons, 2003.

[4] T. Homma, N. Kunito, S. Kamado. Fabrication of extraordinary high-strength magnesium alloy by hot extrusion. Scripta Materialia 61(6):644-647, 2009.

[5] A. C. Fischer-Cripps. Introduction to contact mechanics, vol. 87. Springer, 2000.

[6] F. A. Stevie, L. Giannuzzi, B. Prenitzer. The focused ion beam instrument. In Introduction to Focused Ion Beams, pp. 1-12. Springer, 2005.

[7] S. Reyntjens, R. Puers. A review of focused ion beam applications in microsystem technology. Journal of micromechanics and microengineering 11(4):287, 2001.

[8] R. Hearmon. The elastic constants of anisotropic materials. Reviews of Modern Physics 18(3):409, 1946.

[9] M. A. Kumar, I. J. Beyerlein, R. J. McCabe, C. N. Tome. Grain neighbour effects on twin transmission in hexagonal close-packed materials. Nature communications 7:13826, 2016.

[10] J. Nemecek, J. Nemecek, J. Manak. Fracture properties of cement studied by nanoindentation and fib In Press 2018.

[11] ANSYS, Inc. Ansys reference manual version 17.2, 2017. https://www .ansys.com/

[12] C. Sun, N. Guo, M. Fu, S. Wang. Modeling of slip, twinning and transformation induced plastic deformation for twip steel based on crystal plasticity. International journal of plasticity 76:186-212, 2016. 